\title{
ANATOMIA DA MADEIRA E CASCA DE Acacia velutina DC.
}

\author{
José Newton Cardoso Marchiori \\ Departamento de Ciências Florestais - Centro de Ciências Rurais \\ UFSM - Santa Maria, RS
}

\section{RESUMO}

O trabalho descreve a estrutura anatômica da madeira e da casca de Acacia velutina DC. Os detalhes anatômicos desta liana são comparados com referências da literatura para outras espécies sul-americanas do mesmo gênero. Dentre os principais caracteres observados na madeira destacam-se a presença de septos em fibras, os raios com geralmente 3-4 células de largura e os canais intercelulares axiais de natureza traumática. Para a casca salientam-se as fibras floemáticas, a ausência de cristais nos raios e seu curso irregular na casca mediana.

Palavras-chave : Anatomia da Madeira, Anatomia da Casca, Acacia, Acacia vehtina DC., Leguminosae, Mimosoideae, Mimosaceae.

\section{SUMMARY}

The wood and bark of Acacia vehtitina DC. are described and compared with some other South-American species of the same genus. The presence of septa in fibres, the traumatic longitudinal channels and the 3-4 cells wide rays are the most important features of the wood structure. Phloematic fibres in the inner bark, the absence of chrystals in ray cells and their irregular course in the middle bark are important features in the anatomy of the bark.

Keywords : Wood Anatomy, Bark Anatomy, Acacia, Acacia velutina DC., Leguminosae, Mimosoideae, Mimosaceae. 


\section{INTRODUÇÃO}

O gênero Acacia (Tournefort) Miller compreende cerca de 1.200 espécies (PEDLEY, 1986), que se distribuem amplamente pelas regiões tropicais da América, África, Ásia e Australia. O gênero encontra-se ausente apenas nas floras da Europa e Nova Zelândia. (BURKART, 1952)

Acacia velutina DC. é uma liana aculeada, de até $20 \mathrm{~m}$ de altura, originária do sul do Brasil, Paraguai e Misiones (Argentina). No Rio Grande do Sul, é encontrado apenas na metade norte do Estado, na área da floresta pluvial (RAMBO, 1966). A espécie é conhecida popularmente como nhapindá, vamos-junto (BURKART, 1979); juqueri e uña-de-gato (CIALDELLA, 1984).

A espécie em estudo é encontrada tanto no interior das matas situadas em solos úmidos ou rochosos, como em clareiras, capoeiras, beira de rios e caminhos, onde por vezes chega a se tornar freqüente (BURKART, 1979).

Sob o ponto de vista taxonômico, a espécie classifica-se na série Vulgares Bentham ou sub-gênero Aculeiferum Vassal, por apresentar estipulas não espinecescentes, folhas bipinadas e acúleos internodais dispersos.

O presente estudo visa a descrição anatômica de sua madeira e casca, aspectos ainda não investigados cientificamente.

\section{REVISÃO DE LITERATURA}

O gênero Acacia foi classificado por BENTHAM (1842) em seis séries botânicas, com base em caracteres clássicos da morfologia floral e do aparelho vegetativo: Vulgares, Filicinae, Gummiferae, Botryocephalae, Phyllodineae e Pulchellae. Destas, apenas as três primeiras possuem representantes na flora americana.

VASSAL $(1963,72)$ propôs mais recentemente uma nova classificação natural, baseada em caracteres filéticos da morfologia da semente e plântulas. Suas observações levaram-no a restaurar o gênero monotípico Faidherbia ( $F$. albida (Del.) A. Chev.) e a dividir Acacia nos subgêneros Aculeiferum, Acacia e Heterophyllum. De acordo com o leguminólogo francês, Aculeiferum baseia-se nas séries Vulgares e Filicinae anteriormente referidas, o sub-gênero Acacia compreende as espécies da série Gummiferae, com exceção de Acacia albida Del., e Heterophyllum reúne as séries Botryocephalae, Phyllodineae e Pulchellae, de Bentham.

Com relação à Anatomia da Madeira, a literatura é bastante escassa, face à importância econômica e extensão do gênero. Mesmo em obras clásssicas, as referências são 
sumamente pobres. RECORD \& HESS ( 1954), por exemplo, não tratam do mesmo, apesar das centenas de espécies nativas no continente americano.

COZZO (1951), em importante estudo sobre a anatomia da madeira das leguminosas mimosoídeas e cesalpinioídeas argentinas, observou que Acacia constitui um grupo estruturalmente homogêneo, não ocorrendo diferenças anatômicas de maior vulto. $\mathrm{O}$ autor relacionou uma série de detalhes estruturais, colhidos da análise de treze espécies e fornece uma chave dicotômica para a identificação das mesmas, com base em caracteres anatômicos.

MARCHIORI (1980) estudou a anatomia da madeira e casca de Acacia caven (Mol.) Mol., Acacia tucumanensis Gris. e Acacia bonariensis Gill. ex Hook. et Arn. Suas obsevações indicaram grande semelhança estrutural entre as duas espécies da série Vulgares Benth. ( $A$. bonariensis, A. tucumanensis) e diferenças importantes entre estas e Acacia caven, pertencente à série Gummiferae. Para a distinção destas 3 espécies, o autor baseou-se na presença ou não de septos em fibras, no arranjo do parênquima axial e na morfologia dos raios.

ROBERTSE et al. (1980), em estudo de 37 espécies sul-africanas, encontraram pouca variação anatômica na madeira. A dimensão dos raios e, com menor importância, a presença de anéis de crescimento, número de poros por $\mathrm{mm}^{2}$ e distribuição do parênquima axial, foram os principais caracteres utilizados para a separação dos sub-gêneros de Acacia. Os autores salientam que todas as 14 espécies examinadas do sub-gênero Aculeiferum tem raios estreitos (2-5-seriados), ao passo que as 23 espécies do sub-gênero Acacia, distinguem-se por terem raios mais largos (4-14seriados).

Em estudo descritivo da madeira de Acacia caven (Mol.) Mol., MARCHIORI (1992) destacou a ausência de septos em fibras, a abundância do parênquima axial e a elevada percentagem de raios com mais de 4 células de largura, como seus caracteres mais importantes. Tais aspectos foram interpretados pelo autor como de valor taxonômico para a série Gummiferae Benth., na qual a espécie se insere. Para a estrutura da casca, foi destacado o arranjo das fibras floemáticas em faixas tangenciais regulares, rodeadas por séries cristaliferas. A madeira desta espécie foi também estudada por WIEDENBRUG (1948) e TORTORELLI (1956).

Para Acacia ibirocayensis, MARCHIORI (1993) registrou a ausência de septos em fibras, o abundante parênquima axial em faixas tangenciais irregulares e raios tri e tetrasseriados. Tais aspectos foram considerados pelo autor como sugestivos da série Gummiferae Benth., na qual a espécie se insere.

Na descrição da madeira de Acacia recurva Benth., MARCHIORI (1982) destacou a presença de fibras libriformes septadas, de parênquima axial pouco abundante, de fibras vivas com 
paredes finas na periferia do parênquima paratraqueal e de raios predominantemente uni e bisseriados. Estes caracteres foram referidos pelo autor como freqüentes nas espécies nativas da série Vulgares Benth.

A madeira de Acacia nitidifolia Speg. apresenta caracteres similares à espécie acima referida, de acordo com MARCHIORI (1991.A). O autor relacionou para a mesma a presença de porosidade difusa, elementos vasculares curtos, placas de perfuração simples, pontuações intervasculares alternas e ornamentadas, parênquima axial dos tipos vasicêntrico e marginal cristalifero, raios homogêneos 2-3-seriados e fibras libriformes. Estes dois últimos aspectos anatômicos foram interpretados pelo autor como indicativos da Série Vulgares Benth. ou subgênero Aculeiferum Vassal. A observação adicional de canais intercelulares axiais de origem traumática foi registrada como importante novidade anatômica.

Para Acacia plumosa Lowe, também pertencente à série Vulgares Benth., MARCHIORI (1991.B) confirmou a presença de raios estreitos e fibras septadas, destacando a importância destes caracteres para a taxonomia interna do gênero. A presença de canais intercelulares axiais e de canais celulares na estrutura radial foram ainda interpretados como de grande importância taxonômica.

GHOSH \& PURKAYASTHA (1962) observaram que a goma de Acacia senegal Willd. é produzida em cistos formados na casca interna de algurmas árvores, organizando-se em fileiras tangenciais no parênquima floemático axial seriado, adjacente à região cambial.

A literatura produzida sobre a anatomia da casca é relativamente pequena em comparação com a madeira. Os trabalhos relativos a leguminosas sul-americanas são em número ainda mais reduzido.

JOLY \& TEIXEIRA (1958) descreveram a anatomia da casca do guapuruvú (Schizolobium parahyba (Vell.) Blake).

TEIXEIRA et al. (1979) investigaram a estrutura da casca de 4 espécies de Dalbergia, nativas do Brasil. Para a identificação das mesmas foi elaborada uma chave dicotômica, com base em características do floema secundário.

ROTH (1977) estudou a anatomia da casca de 22 espécies arbóreas da floresta tropical pluvial da Guiana Venezuelana, pertencentes a 7 diferentes gêneros de Mimosoideae. Os gêneros Acacia e Mimosa, não foram contudo incluídos. A autora concluiu que a casca em Mimosoideae assemelha-se às de Sapotaceae, quanto ao agrupamento do líber duro e formação de células secretoras. Com relação à anatomia, Ingrid Roth destacou ainda que a sub-familia constitui Im grupo relativamente homogêneo, apresentando as seguintes características em comum : 
- O líber duro ocorre na forma de fibras típicas, agrupadas em estreitas placas tangenciais, não havendo células pétreas na casca interna;

- Embora multisseriados, os raios não alcançam largura considerável;

- Não ocorrem canais secretores, mas apenas células secretoras em curtas fileiras tangenciais;

- O crescimento de dilatação é moderado, formando-se células pétreas no final da casca mediana;

- O súber é tipicamente estratificado e o feloderma desenvolve células pétreas, tendendo à estratificação.

Em estudo de 3 espécies sul-brasileiras de Acacia, MARCHIORI (1980) reconheceu diferenças de valor taxonômico para os subgêneros Aculeiferım e Acacia. Segundo o mesmo autor, as espécies do primeiro destes sub-gêneros distinguem-se pela presença de fibras libriformes septadas, de liber duro em feixes isolados que tendem ao alinhamento tangencial, e pela ausência de monocristais prismáticos de oxalato de cálcio em células de parênquima radial. Para o subgênero Acacia, foi destacado o líber duro em faixas tangenciais regulares, interrompidas apenas por raios floemáticos, a presença de cristais em raios e de fibras floemáticas não septadas.

Para Acacia recurva Benth., MARCHIORI (1982) reporta a presença de fibras floemáticas em feixes alinhados tangencialmente e rodeados por séries de câmaras cristaliferas. São também referidos a presença de raios homogêneos geralmente multisseriados e desprovidos de canais, a ausência de canais secretores e um crescimento moderado de dilatação, havendo a formação e concentração de células pétreas e macroesclerócitos na região mais externa da casca mediana. Tais aspectos foram considerados pelo autor como peculiares ao subgênero Aculeiferum Vassal.

\section{MATERIAL E MÉTODOS}

O material em estudo é procedente de Itapiranga, no oeste de Santa Catarina. Consiste da amostra de madeira relativa à coleta $\mathrm{n}^{\circ} 17.076$, realizada por Reitz \& Klein a 9/12/1964. Os registros indicam que a mesma foi obtida à beira do rio e a liana apresentava flores brancas.

Da amostra de madeira foram preparados três bloquinhos, orientados para a obtenção de cortes anatômicos nos planos transversal, longitudinal radial e longitudinal tangencial. Os bloquinhos, contendo tecidos da madeira e casca, foram retirados na periferia do alburno e 
amolecidos por fervura em água.

Os cortes anatômicos foram realizados em micrótomo de deslizamento, com espessura nominal de $20 \mu \mathrm{m}$. Foram coloridos por vermelho-de-acridina, crisoidina e azul-de-astra (DUJARDIN, 1964), e montados em lâminas permanentes.

A dissociação de fragmentos de madeira e casca foi realizada pelo método de Jeffrey (FREUND, 1970). Na coloração do macerado usou-se apenas safranina.

Para a determinação dos dados quantitativos da estrutura anatômica da madeira seguiu-se as recomendações da COPANT (1973), com alterações adotadas por BURGER (1979). As determinações histométricas do xilema foram realizadas de acordo com a metodologia proposta por TEIXEIRA (1977) e MARCHIORI (1980)

Para a casca foram determinados apenas o comprimento e o diâmetro médio de elementos crivados e fibras floemáticas, com base em 20 medições para cada caráter anatômico.

\section{DESCRIÇÃO DA MADEIRA}

\section{Caracteres gerais :}

Cerne e alburno indistintos. Madeira de cor amarela (HUE 2,5 Y8/6), com brilho acentuado, de grã direita, macia, não aromática e de textura média. Figura homogênea.

\section{Caracteres macroscópicos :}

Parênquima axial : Visivel apenas com lente de $10 \mathrm{X}$; escasso, em disposição paratraqueal vasicêntrica até confluente e simulando faixas marginais.

Raios : Visíveis a olho nu em plano transversal, finos, pouco freqüentes. Visiveis sem dificuldade sob lente de $10 \mathrm{X}$ em plano longitudinal tangencial; baixos, não estratificados. Espelhado dos raios pouco contrastado.

Poros : Visiveis a olho nu, de diâmetro médio e muito numerosos. Poros solitários e em múltiplos de 2 a 5 , formando agrupamentos radiais, menos freqüentemente racemiformes. Conteúdo de cor vermelho-escura em numerosos poros. Linhas vasculares retilíneas. 
Outros caracteres: Canais secretores axiais, de natureza traumática, presentes na madeira em linhas tangenciais ocasionais. Máculas medulares, líber incluso, listrado de estratificação e canais intercelulares radiais, ausentes

\section{Caracteres microscópicos}

Vasos : Distribuídos em anéis semi-porosos, muito numerosos $\left(16-29-50 / \mathrm{mm}^{2}\right)$ e ocupando cerca de $27 \%$ da secção transversal da madeira. Poros solitários e em múltiplos radiais e racemiformes, associando freqüentemente 1 ou 2 poros maiores com numerosos de diâmetro muito pequeno (Figura 1. A,B,D; 3.A; 4.B). Poros de diâmetro médio (75 - $143-228 \mu \mathrm{m}$ ), de secção circular a oval (Figura 1.A-D) e paredes espessas $(2,5-4,3-6,3 \mu \mathrm{m})$.

Elementos vasculares curtos (217 - $345-463 \mu \mathrm{m}$ ), com placas de perfuração simples (Figura 2.A) em posição obliqua até transversal ao vaso. Apêndices curtos (15-49-95 $\mu \mathrm{m})$, presentes em uma ou em ambas as extremidades. Espessamentos espiralados ausentes.

Pontuações intervasculares pequenas $(5,5-6,5-7 \mu \mathrm{m})$, alternas, ovais e ornamentadas; com abertura lenticular, horizontal, inclusa ou coalescente a poucas pontuações.

Pontuações raio-vasculares pequenas $(3,5-5-7 \mu \mathrm{m})$ e arredondadas. Pontuações parênquimovasculares também pequenas $(5-5,8-7 \mu \mathrm{m})$, semelhantes às raio-vasculares.

Conteúdo com o aspecto de resina, freqüente em poros e vasos, sobretudo no cerne (Figura 1.D). Tilos ausentes

Parênquima axial: Abundante, ocupando $31,7 \%$ do volume da madeira e em disposição paratraqueal, desde vasicêntrica até confluente e formando faixas tangenciais irregulares (Figura 1.D).

Células fusiformes com 130 - 233 - $358 \mu \mathrm{m}$ de altura por 11 - $16-28 \mu \mathrm{m}$ de largura.

Séries parenquimáticas com $180-259-380 \mu \mathrm{m}$ de altura por $9-17-53 \mu \mathrm{m}$ de diâmetro, compostas por 2 a 4 células (Figura 2.A).

Cristais romboédricos de oxalato de cálcio, presentes em séries de aproximadamente 16 câmaras, localizadas na periferia do parênquima paratraqueal e no lenho tardio (Figura 1. B,C).

Raios : Pouco numerosos (4 - 5,7 - 8/mm), ocupando $11 \%$ do volume da madeira. Tecido radial homogêneo, composto inteiramente de células horizontais (Figura 2.D; 3.C,D). Raios de relacionamento normal. Raios agregados e fusionados ausentes (Figura 2.A-C).

Raios unisseriados pouco abundantes $(6,3 \%$ do total); muito baixos $(32-81-175 \mu \mathrm{m})$, 
extremamente finos $(6-11-20 \mu \mathrm{m})$ e com 2 - 6 - 15 células de altura.

Raios multisseriados (Figura 2.A-C) com 3 células de largura em sua maioria (44,2\%), menos freqüentemente tetrasseriados $(29 \%)$ e bisseriados $(13,2 \%)$, raramente com mais de 4 células de largura $(7,3 \%)$; de baixos a medianos $(155-376-713 \mu \mathrm{m})$, com $15-31$ - 57 células de altura e de muito finos a finos $(20-29-41 \mu \mathrm{m})$.

Células cristaliferas, envolventes, eretas, esclerosadas, latericuliformes, oleiferas e quadradas, ausentes no tecido radial.
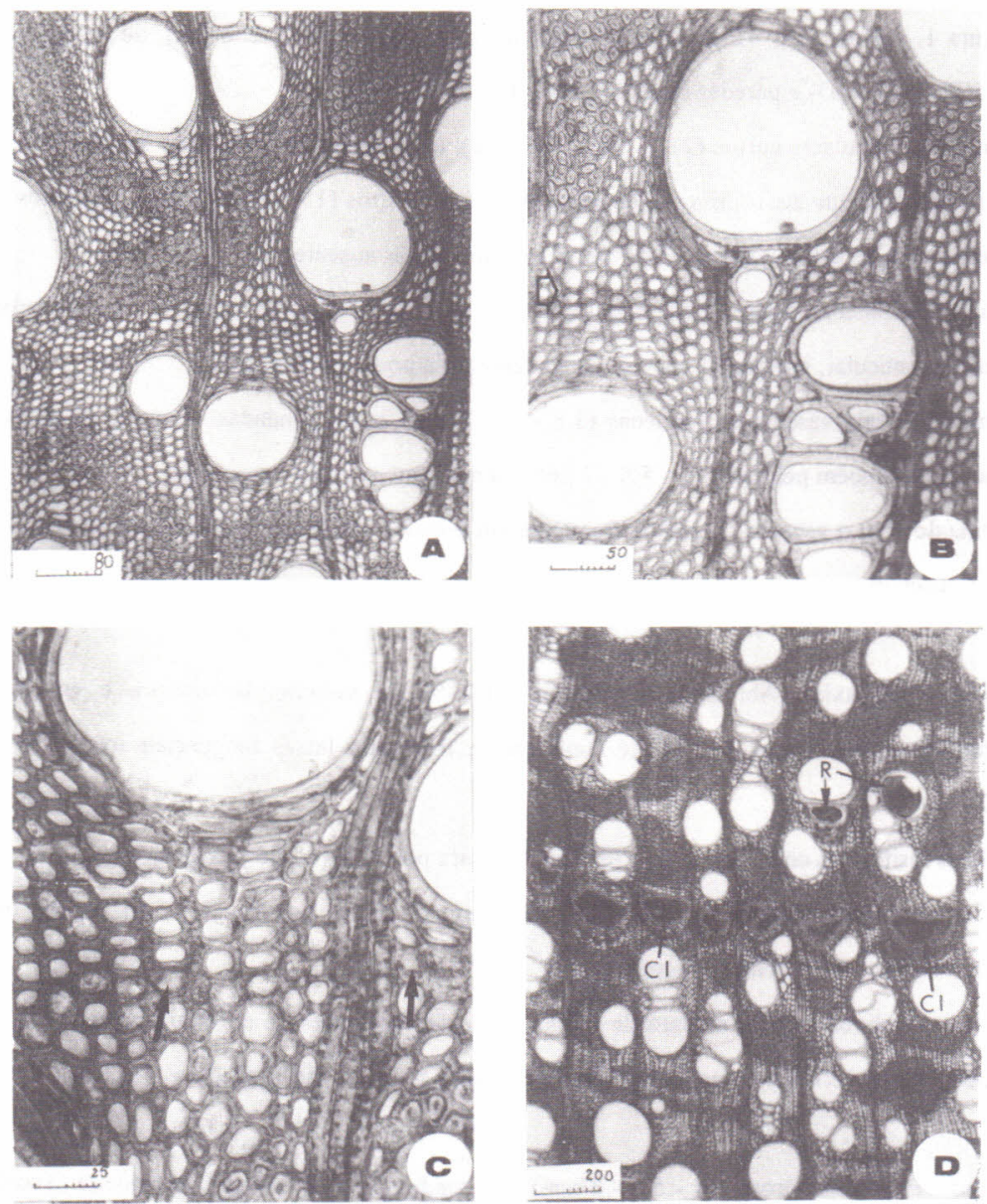

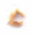

FIGURA 1. Aspectos da secção transversal da madeira de Acacia velutina. A Detalhe de um limite de anel de crescimento (setas). B Concentração de fibras e séries cristalíferas no lenho tardio (setas). C Mesmo detalhe, mas com maior aumento. D Aspecto geral, destacando os canais intercelulares axiais (CI) tangencialmente dispostos e a presença de resina (R) em vasos e nos referidos canais. 

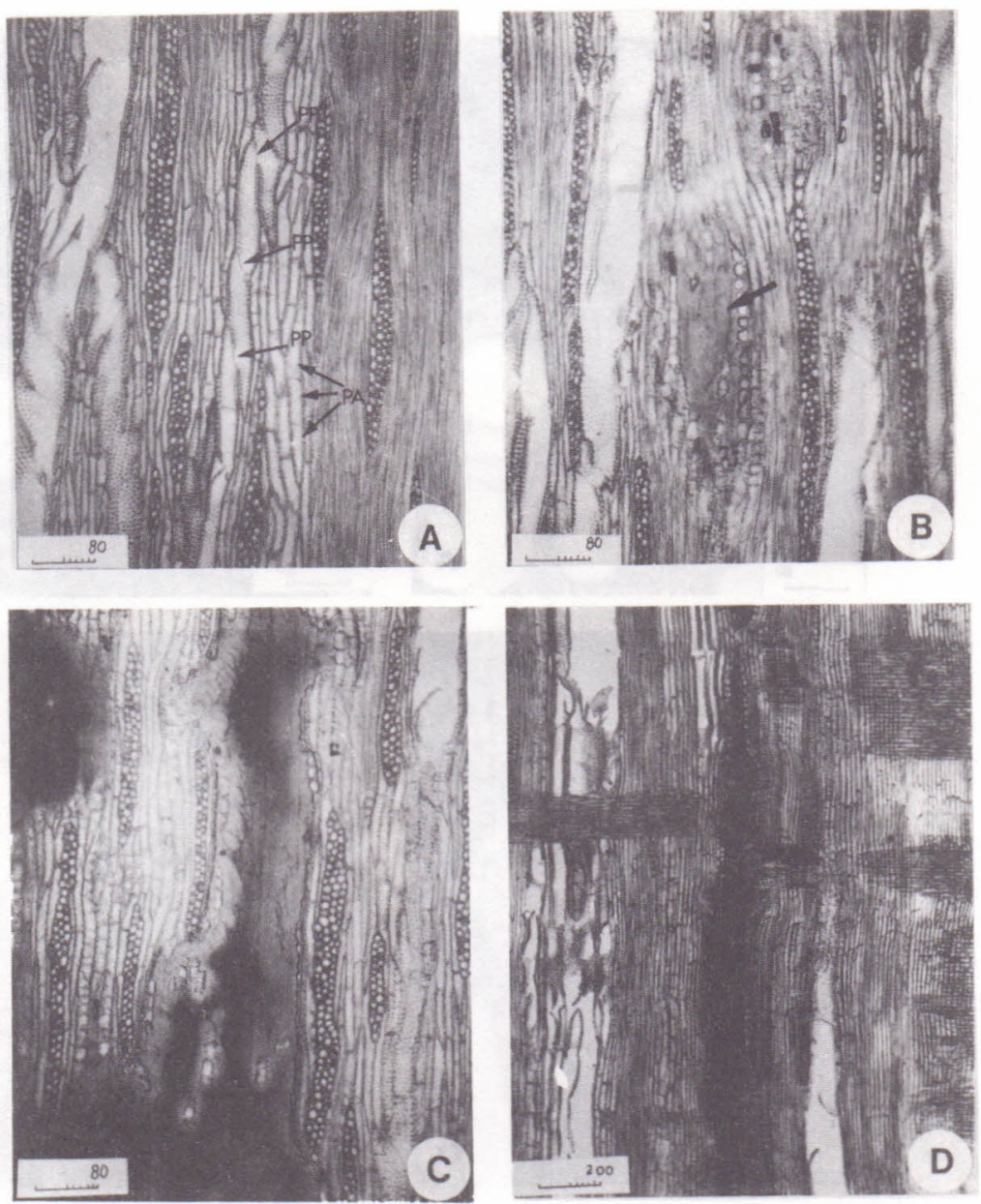

FIGURA 2. Aspectos da madeira em secções longitudinais de Acacia velutina. A Seç̧ão tangencial, destacando placas de perfuração simples em vasos (PP) e séries de parênquima axial (PA). B Secção tangencial mostrando canal intercelular axial (seta) e raios multisseriados $\mathbf{C}$ Secção tangencial, salientando o conteúdo de resina nos canais intercelulares axiais. D Secção radial, destacando a homogeneidade dos raios.

Fibras : Tecido fibroso pouco abundante, ocupando apenas $30 \%$ do volume da madeira. Fibras libriformes, septadas, freqüentemente gelatinosas e providas de pontuações simples diminutas. Fibras curtas $(930-1.165-1.420 \mu \mathrm{m})$, estreitas $(10-14-19 \mu \mathrm{m})$ e com paredes muito espessas $(3,8-5,7-7,5 \mu \mathrm{m})$. 

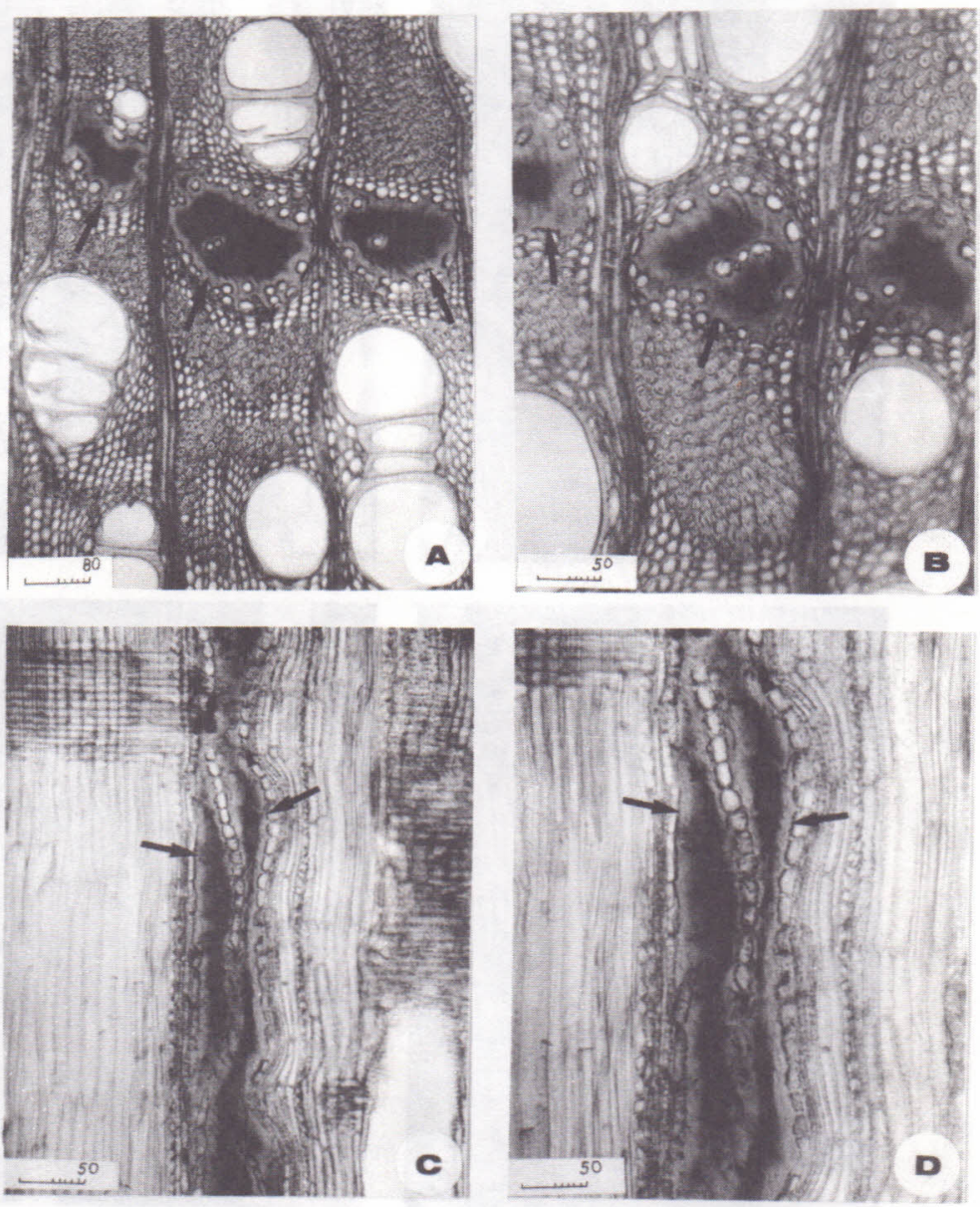

FIGURA 3. Detalhes dos canais intercelulares axiais da madeira de Acacia velutina. A-B Aspectodos canais (setas), em corte transversal e com diferentes aumentos. C-D Cortes radiais em diferentes aumentos, mostrando raios compostos inteiramente de células horizontais e canal (setas) com resina.

Outros caracteres: Canais intercelulares axiais de natureza traumática, preenchidos com resina e dispostos em grupos tangenciais (Figura 1.D; 2.B,C,D; 3. A-D). Tubos laticiferos e taniniferos, liber incluso, máculas medulares e estratificação, ausentes. Anéis de crescimento distintos, marcados pela concentração de fibras, a formação de uma estreita bainha de séries cristalíferas no término do anel e a concentração de células parenquimáticas no início do anel seguinte (Figura 1.A-C). 


\section{DESCRIÇÃO DA CASCA}

Casca interna : Estreita, medindo cerca de $250 \mu \mathrm{m}$ de espessura (Figura 4.A-B). Líber duro composto por fibras de paredes muito espessas e lignificadas, compondo faixas tangenciais retangulares em plano transversal, com 3 a 6 células de espessura e interrompidas apenas pelos raios. Na periferia do liber duro encontram-se cristais romboédricos de oxalato de cálcio em longas séries de câmaras. Fibras floemáticas desprovidas de septos, medindo de $1.180-1.400-1500 \mu \mathrm{m}$ de comprimento por 20 - $28-35 \mu \mathrm{m}$ de diâmetro

Elementos crivados de $220-330-400 \mu \mathrm{m}$ de comprimento por $20-28-35 \mu \mathrm{m}$ de diâmetro tangencial. Reúnem-se em grupos tangenciais no líber tenro, juntamente com células de parênquima floemático axial e células acompanhantes. Apresentam numerosos poros muito pequenos em cada área crivada. As placas crivadas são verticais, reunindo de 15 a 25 áreas crivadas em arranjo reticulado.

Parênquima axial abundante. Células acompanhantes desprovidas de inclusões inorgânicas.

Casca Mediana : Bastante larga em relação ao total da casca, com cerca de $2.000 \mu \mathrm{m}$ de espessura. $\mathrm{O}$ colapso de tubos crivados ocorre simultaneamente à formação de novas células parenquimáticas e à diferenciação de células oleiferas. Estas são mais longas do que as células do parênquima axial e se distinguem em secção transversal por terem maior diâmetro do que as demais do liber tenro (Figura 4.A-B).

As células parenquimáticas dividem-se anticlinalmente segundo o plano raio-longitudinal (Figura 4.D). Ao final da casca mediana forma-se uma estreita faixa de esclereidas e grupos associados de fibras corticais (Figura 4.C).

Casca externa : Estreita nos material examinado, medindo cerca de $300 \mu \mathrm{m}$ de espessura. Consiste de várias peridermes concêntricas (Figura 4.C) e apresenta células de súber com faces tangenciais da parede ligeiramente mais espessas do que as radiais. São freqüentes as células felóides, tanto isoladamente como em curtas linhas tangenciais.

\section{ANÁLISE DA ESTRUTURA ANATÔMICA}

Os principais caracteres anatômicos observados na madeira de Acacia velutina DC., tais como elementos vasculares curtos, placas de perfuração simples, pontuado intervascular alterno, 

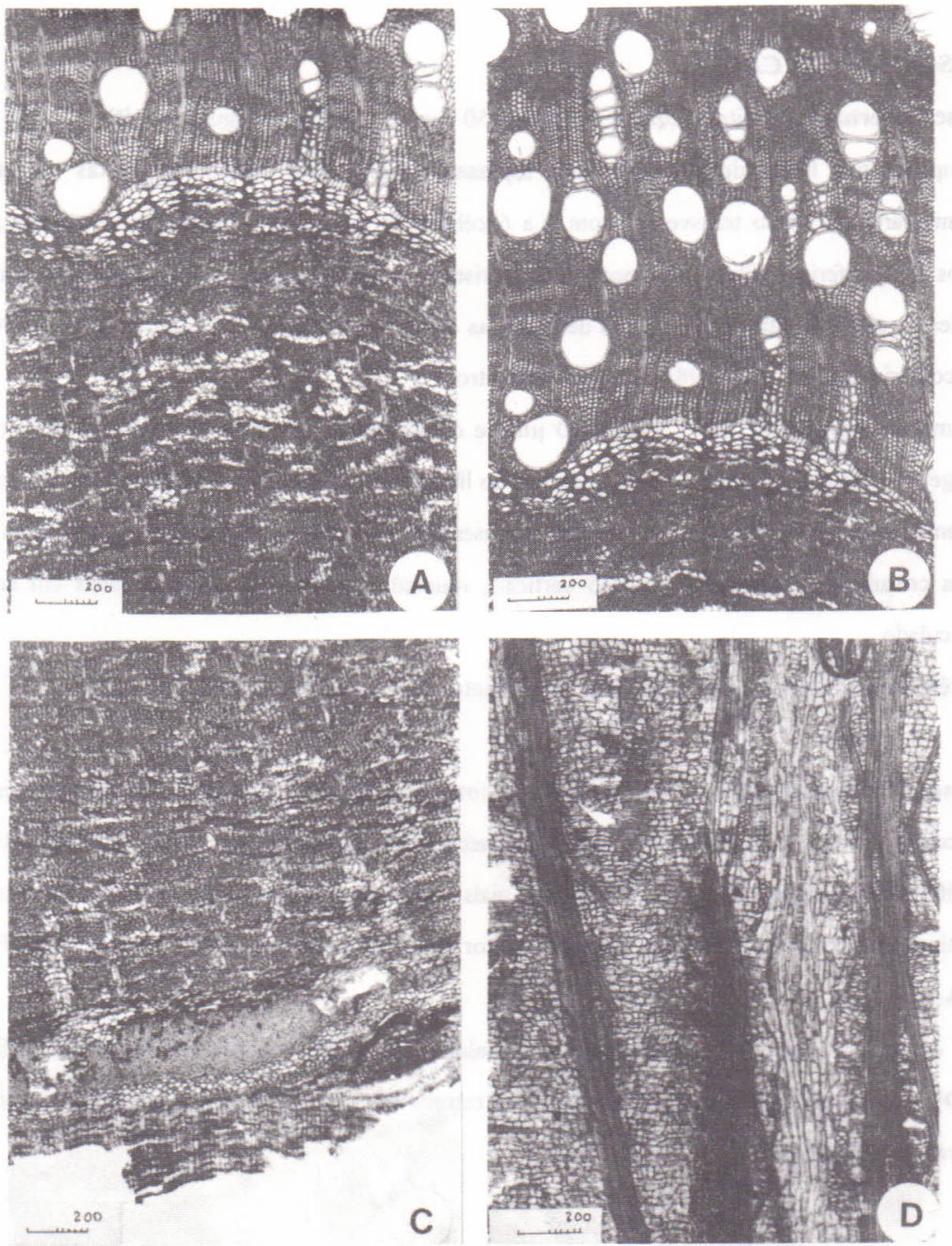

b

4

FIGURA 4. Detalhes da estrutura anatômica da casca de Acacia recurva. A-B Secção transversal, incluindo a madeira, a casca interna e parte da casca mediana. C Aspecto da casca mediana, com destaque para um grupo de fibras corticais (F) e o ritidoma. D. Aspecto tangencial da casca mediana, mostrando o alinhamento tangencial das células parenquimáticas, resultante de divisões celulares segundo planos anticlinais raiolongitudinais.

pontuações ornamentadas de diâmetro pequeno, parênquima paratraqueal, raios homogêneos e

fibras libriformes, tem ocorrência generalizada em leguminosas, de acordo com as referência de COZZO (1950,51), METCALFE \& CHALK (1972), RECORD \& HESS (1949) e TORTORELLI 
A ausência de estratificação, associada a raios de células procumbentes e seç̧ão pequena, identificam, segundo BARETTA-KUIPERS (1981) a sub-familia Mimosoideae, dentro de Leguminosae

A presença de fibras septadas na espécie em estudo, corresponde ao observado por MARCHIORI (1980) para Acacia bonariensis e Acacia tucumanensis, bem como para Acacia recurva (MARCHIORI, 1982), Acacia mitidifolia (MARCHIORI, 1991.A) e Acacia plumosa (MARCHIORI, 1991.B). Todas estas espécies pertencem à mesma série Vulgares Benth. (= subgênero Aculeiferum Vassal), reforçando o valor do caráter para este táxon infra-genérico.

Para a identificação de Acacia velutina DC. são ainda importantes a presença de cristais em séries de aproximadamente 16 câmaras, localizadas na periferia do parênquima paratraqueal, no lenho tardio e no término do anel de crescimento, bem como a presença de canais intercelulares axiais de natureza traumática, dispostos em grupos tangenciais.

A casca de Acacia velutina assemelha-se ao descrito por MARCHIORI $(1980,82)$ para outras espécies sul-brasileiras, pertencentes ao mesmo sub-gênero Aculeiferum Vassal

\section{REFERÊNCIAS BIBLIOGRÁFICAS}

1. BARETTA-KUIPERS, T. Wood Anatomy of Leguminosae - its relevance to Taxonomy. In: POLHILL, R.M. \& RAVEN, P.H. Advances in Legume Systematics. 1981. p. 677-715.

2. BENTHAM, G. Notes on Mimoseae, with a synopsis of species. The London Journal of Botany, 1: 318-392; 494-518, 1842

3. BURGER, L.M. Estudo anatômico do xilema secundário de sete espécies do gênero Dalbergia, Leguminosae Faboideae. Curitiba, 1979. 184 f. Dissertação. Mestrado. Universidade Federal do Paraná. Setor de Ciências Agrárias. Curso de Pós-Graduação em Engenharia Florestal.

4. BURKART, A. Las Leguminosas Argentinas Silvestres y Cultivadas. Buenos Aires, ACME, 1952. $569 \mathrm{p}$

5. BURKART, A. Leguminosas Mimosoideas. In : REITZ, R. Flora Ilustrada Catarinense. Itajai, 1979. 299 p.

6. CIALDELLA, E.M. El género Acacia en la Argentina. Darwiniana, 25(1-4): 59-111, 1984.

7. COPANT - COMISION PANAMERICANA DE NORMAS TECNICAS. 0:1-019, novembro, 1973.

8. COZZO, D. Anatomia del leño secundario de las Leguminosas Papilionoideas argentinas. Rev. Inst. Nac. Invest. Ci. Nat. Ci. Bot., 1(7): 223-361, 1950

9. COZZO, D. Anatomia del leño secundario de las Leguminosas Mimosoideas y Caesalpinoideas 
argentinas silvestres y cultivadas. Rev. Inst. Nac. Invest. Ci. Nat. Ci. Bot., 2(2): 63-290, 1951

10. DUJARDIN, E.P. Eine neue holz-zellulosenfaerbung. Mikrokosmos, 53: 94, 1964.

11. FREUND, H. Handbuch der Mikroskopie in der Technik. Frankfurt, Umsham Verlag, 1970. $375 \mathrm{p}$

12. GHOSH, S.S. \& PURKAYASTHA, S.K. Anatomical studies of wood and bark of Acacia senegal Willd. trees with special reference to gum exsudation. Indian For., 88(2): 92-99, 1962.

13. JOLY, A.B. \& TEIXEIRA, O. Observações sobre a anatomia da casca do guapuruvu, Schizolobium parahyba (Vell.) Blake. B. Fac. Filos. Ciênc. Letras USP, 224: 81-100, 1958.

14. MARCHIORI, J.N.C. Estudo anatômico do xilema secundário e da casca de algumas espécies dos gêneros Acacia e Mimosa, nativas no Estado do Rio Grande do Sul Curitiba, 1980. 186 f. Dissertação. Mestrado. Universidade Federal do Paraná. Setor de Ciências Agrárias. Curso de Pós-Graduação em Engenharia Florestal.

15. MARCHIORI, J.N.C. Estudo anatômico do xilema secundário e da casca de Acacia recurva Benth. (Leguminosae Mimosoideae). Ciência e Natura, 4: 95-105, 1982

16. MARCHIORI, J.N.C. Anatomia da madeira de Acacia nitidifolia Speg. (Leguminosae Mimosoideae. Ciência Florestal, 1(1): 46-63, 1991.A.

17. MARCHIORI, J.N.C. Anatomia da madeira de Acacia plumosa Lowe (Leguminosae Mimosoideae). Ciência e Natura, 13: 67-77, 1991.B

18. MARCHIORI, J.N.C. Anatomia da madeira e casca do espinilho, Acacia caven (Mol.) Mol Ciência Florestal, 2(1): 27-47, 1992

19. MARCHIORI, J.N.C. Estudo anatômico do xilema secundário de Acacia ibirocayensis Marchiori (Leguminosae Mimosoideae). Ciência e Natura, 15: 149-159, 1993.

20. METCALFE, C.R. \& CHALK, L. Anatomy of the Dicotyledons. Oxford, Clarendon Press, 1972. $1500 \mathrm{p}$

21. PEDLEY, L. Derivation and dispersal of Acacia (Leguminosae), with particular reference to Australia, and the recognition of Senegalia and Rhacosperma. Bot. J. Linn. Soc., 92: 219254,1986

22. RAMBO, B. Leguminosae riograndenses. Pesquisas, Série Botânica, n² 23, 1966. 166 p

23. RECORD, S.J. \& HESS, R.W. Timbers of the New World. New Haven, Yale University Press, 1954.640 p.

24. ROBBERTSE, P.J.; VENTER, G. \& RENSBURG, H.J. van. The Wood Anatomy of the South African Acacias. IAWA Bull., 1(3):93-103, 1980.

25. ROTH, I. Estructura anatomica de la corteza de algunas especies arboreas venezolanas de Mimosaceae. Acta Botanica Venezuelica, 12(1-4): 293-355, 1977.

6. TEIXEIRA, L.L. Identificação botânico-dendrológica e anatômica da madeira de seis espécies euxilóforas do sudoeste paranaense. Curitiba, 1977. 112 f. Dissertação. Mestrado. Universidade Federal do Paraná. Setor de Ciências Agrárias. Curso de PósGraduação em Engenharia Florestal. 
27. TEIXEIRA, L.L.; BURGER, L.M. \& KARSTEDT, P. Estudos microscópicos do xilema e casca do gênero Dalbergia, baseados em quatro espécies do sul do Brasil. Arq. J. Bot., 22: 115 133,1979

28. TORTORELLI, L.A. Maderas y Bosques Argentinos. Buenos Aires, ACME, 1956. 910 p.

29. VASSAL, J. Intérêt taxonomique dans la morphologie des graines dans le genre Acacia. Bull. de la Societé d'Histoire Naturel, Toulouse, 98(3-4): 341-371, 1963

30. VASSAL, J. Ontogenetic and seed research applied to the morphological, taxonomical and phylogenetic study of the genus Acacia. Travaux Lab. For. Toulouse. Tome 1, vol. 8, art. 17, 1972. 125 p. (Resumo).

31. WIEDENBRUG, W. Maderas Chilenas - contribuicion a su anatomia y identificacion. Lilloa, 16: $262-375,1948$. 
TABELA 1. Dados quantitativos da estrutura anatômica da madeira de Acacia recurva.

\begin{tabular}{|c|c|c|c|c|}
\hline CARACTERÍSTICA & $\begin{array}{c}\text { VALOR } \\
\text { MÍNIMO }\end{array}$ & MÉDIA & $\begin{array}{r}\text { VALOR } \\
\text { MÁXIMO }\end{array}$ & $\begin{array}{r}\text { DESVIO } \\
\text { PADRÃO }\end{array}$ \\
\hline 1. Fração de poros (\%) & 22,0 & 27,3 & 35,0 & 4,63 \\
\hline 2. Freqüência de poros (poros $/ \mathrm{mm}^{2}$ ) & 16,0 & 29,0 & 50,0 & 9,12 \\
\hline 3. $\emptyset$ poros solitários $(\mu \mathrm{m})$ & 75,0 & 143,0 & 228,0 & 39,47 \\
\hline 4. E. parede de poros $(\mu \mathrm{m})$ & 2,5 & 4,3 & 6,3 & 0,85 \\
\hline 5. C. elementos vasculares $(\mu \mathrm{m})$ & 217,0 & 345,0 & 463,0 & 64,91 \\
\hline 6. C. de apêndices $(\mu \mathrm{m})$ & 15,0 & 49,0 & 95,0 & 20,56 \\
\hline 7. Ø 7. pontuações intervasculares ( $\mu \mathrm{m})$ & 5,5 & 6,5 & 7,0 & 0,48 \\
\hline 8. $\emptyset$ pontuações raio-vasculares $(\mu \mathrm{m})$ & 3,5 & 5,0 & 7,0 & 1,05 \\
\hline 9. Ø pontuações parenquimo-vasc. $(\mu \mathrm{m})$ & 5,0 & 5,8 & 7,0 & 0,63 \\
\hline 10. Fração Parênquima axial (\%) & 26,0 & 31,7 & 36,0 & 3,72 \\
\hline 11. H. séries parênquima axial $(\mu \mathrm{m})$ & 180,0 & 259,0 & 380,0 & 55,84 \\
\hline 12. H. séries parênquima axial (céls.) & 2 & 2,4 & 4 & 0,72 \\
\hline 13. L. séries parênquima axial $(\mu \mathrm{m})$ & 9,0 & 17,0 & 53,0 & 8,53 \\
\hline 14. H. células fusiformes $(\mu \mathrm{m})$ & 130,0 & 233,0 & 358,0 & 50,82 \\
\hline 15. L. células fusiformes $(\mu \mathrm{m})$ & 11,3 & 16,0 & 27,5 & 3,68 \\
\hline 16. Fração tecido radial (\%) & 8,0 & 11,0 & 15,0 & 2,44 \\
\hline 17. Freqüência de raios (raios $/ \mathrm{mm}$ ) & 4 & 5,7 & 8 & 0,99 \\
\hline 18. Fração raios unisseriados (\%) & 3 & 6,3 & 10 & 2,94 \\
\hline 19. H. raios unisseriados $(\mu \mathrm{m})$ & 32,0 & 81,0 & 175,0 & 45,05 \\
\hline 20. H. raios unisseriados (céls.) & 2 & 6 & 15 & 3,48 \\
\hline 21. L. raios unisseriados $(\mu \mathrm{m})$ & 6,3 & 11,3 & 200 & 3,13 \\
\hline 22. H. raios multisseriados $(\mu \mathrm{m})$ & 155,0 & 376,0 & 713,0 & 157,28 \\
\hline 23. H. raios multisseriados (céls.) & 15 & 31 & 57 & 12,67 \\
\hline 24. L. raios multisseriados $(\mu \mathrm{m})$ & 20 & 29,0 & 41,0 & 6,74 \\
\hline 25. L. raios multisseriados (céls.) & 2 & 3,2 & 5 & 0,64 \\
\hline 26. Fração raios 2-seriados (\%) & 8 & 13,2 & 15 & 2,78 \\
\hline 27. Fração raios 3-seriados (\%) & 39 & 44,2 & 51 & 5,19 \\
\hline 28. Fração raios 4-seriados (\%) & 25 & 29,0 & 35 & 3,74 \\
\hline 29. Fração raios com +4 céls. (\%) & 5 & 7,3 & 10 & 2,16 \\
\hline 30. Fração de fibras (\%) & 25 & 30,0 & 32 & 2,60 \\
\hline 31. C. de fibras $(\mu \mathrm{m})$ & 930,0 & 1165,0 & 1420,0 & 118,13 \\
\hline 32. $\emptyset$ de fibras $(\mu \mathrm{m})$ & 10,0 & 14,0 & 19,0 & 1,93 \\
\hline 33. Ø lúmem de fibras $(\mu \mathrm{m})$ & 1,2 & 2,9 & 8,8 & 1,62 \\
\hline 34. E. parede de fibras $(\mu \mathrm{m})$ & 3,8 & 5,7 & 7,5 & 0,87 \\
\hline
\end{tabular}

